\title{
Survival and place of delivery following preterm birth: 1994-96
}

\author{
David Field, Elizabeth S Draper
}

\begin{abstract}
Aim-To compare the survival of premature infants, adjusted for disease severity, in different types of neonatal intensive care setting.

Methods-A prospective observational study in the Trent Health Region was carried out of all infants born to resident mothers at or before 32 weeks of gestation between 1 January 1994 to 31 December 1996 inclusive. The 16 neonatal units in Trent were subdivided into five relatively large units which regularly took outside referrals and 11 smaller units which provided intensive care for a variable proportion (sometimes nearly $100 \%$ ) of their local population. Data regarding obstetric management, neonatal care, and outcome were collected by independent neonatal nurses who visited the units on a regular basis. Survival rates were compared with an expected rate calculated using the Clinical Risk Index for Babies (CRIB). For either setting to be abnormally good or bad actual deaths had to exceed the $95 \%$ confidence interval of the CRIB estimate. Results-Actual survival rates for infants $\leqslant 32$ weeks gestation and for the group of babies $\leqslant 28$ weeks gestation fell within the $\mathbf{9 5 \%}$ confidence interval of the rate predicted by CRIB for both the larger referral units and the smaller district units. Similarly, compared with the CRIB prediction, infants transferred in utero or postnatally were not adversely affected in terms of the number who died.
\end{abstract}

Conclusion-Previous results from this geographical population, showing that survival of babies $\leqslant 28$ weeks gestation was better when their care was provided by referral units, are no longer sustained. Significant changes to the neonatal services over time make the current results plausible. However, the new structure poses potential threats to the teaching, training, and research base of the neonatal service as a whole.

(Arch Dis Child Fetal Neonatal Ed 1999;80:F111-F115)

Keywords: survival; intensive care; CRIB; prematurity

Over the past 10 years there has been a steady growth in the number of neonatal intensive care beds in the UK. ${ }^{1}$ The distribution of these facilities has been the subject of much debate. Discussion has centred on whether neonatal intensive care should be delivered, in most cases, by large tertiary centres or whether smaller, local units can provide the same standard of care.

In a previous report we examined this issue in one region of the UK (Trent) and identified better survival for infants $\leqslant 28$ weeks gestation cared for entirely in referral centres. ${ }^{2}$ That there should be a difference in mortality at that time (1987) was entirely plausible as there were marked differences in the numbers of specialist medical and nursing staff employed in the different types of unit. Furthermore, data from developed countries, albeit limited, supported the concept of improved survival for babies cared for in tertiary centres. ${ }^{34}$

However, our previous study was performed at a time when it was not possible to adjust the observed mortality for variations in case mix between the different types of unit. As a result, we were not able to ensure that our direct comparisons of survival rates were valid.

Subsequently, the National Health Service (NHS) reforms of the early 1990s provided greater autonomy for District Health Authorities (average population 50 000) in determining where to deliver care for their population. This was in contrast to the previous arrangement where Regional Health Authorities (average population 2.5-4 million) took most of the strategic decisions. Given the general perception at the time of the reforms, of a national shortage of neonatal intensive care beds, there was concern that new intensive care units would proliferate. ${ }^{5}$ Recent evidence seems to suggest that such an effect has been limited. ${ }^{6}$ But there is information from the professional bodies that existing district general hospital neonatal services have been strengthened in terms of their ability to deliver intensive care locally. ${ }^{6}$

A second change since 1987 was the introduction of the Clinical Risk Index for Babies (CRIB) which provides a simple tool for assessing initial disease severity of preterm infants. ${ }^{7}$ The performance of individual neonatal units can now be assessed in terms of survival, by comparing actual and expected mortality - that is, corrected for disease severity.

In view of these changes it seemed sensible to repeat our previous study, comparing survival of preterm infants in the Trent Health Region (a geographically defined population) in relation to the type of unit providing the neonatal care. Our aim was to assess whether the policy of relying on district general hospitals to meet a significant proportion of intensive care demand was jeopardising the survival of preterm infants in Trent.

\section{Methods}

The Trent Neonatal Survey (TNS) is an ongoing study of neonatal intensive care activity in 
Table 1 Distribution of infants $\leqslant 32$ gestation weeks between small and large units subdivided by birthweight and gestation - non-transfers only*

\begin{tabular}{|c|c|c|c|c|}
\hline & \multicolumn{2}{|l|}{ Large } & \multicolumn{2}{|l|}{ Small } \\
\hline & All & No died (\%) & All & No died (\%) \\
\hline \multicolumn{5}{|l|}{ Gestation (weeks) } \\
\hline$\leqslant 22$ & 6 & $5(83.3)$ & 3 & $3(100.0)$ \\
\hline $23-24$ & 45 & $35(77.8)$ & 33 & $32(97.0)$ \\
\hline $25-26$ & 102 & $50(49.0)$ & 34 & $19(55.9)$ \\
\hline $27-28$ & 143 & $37(25.9)$ & 89 & $22(24.7)$ \\
\hline $29-30$ & 205 & $18(8.8)$ & 200 & $12(6.0)$ \\
\hline $31-32$ & 447 & $15(3.4)$ & 477 & $8(1.7)$ \\
\hline \multicolumn{5}{|l|}{ Birthweight (g) } \\
\hline$<500$ & 6 & $4(66.7)$ & 5 & $5(100.0)$ \\
\hline $500-749$ & 83 & $57(68.7)$ & 43 & $35(81.4)$ \\
\hline $750-999$ & 126 & $52(41.3)$ & 63 & $21(33.3)$ \\
\hline $1000-1249$ & 155 & $20(12.9)$ & 151 & $17(11.3)$ \\
\hline $1250-1499$ & 189 & $10(5.3)$ & 185 & $9(4.9)$ \\
\hline $1500+$ & 389 & $17(4.4)$ & 389 & $9(2.3)$ \\
\hline Total & 948 & $160(16.9)$ & 836 & $96(11.5)$ \\
\hline \multicolumn{5}{|c|}{ Predicted deaths n (\%) $95 \%$ CI } \\
\hline All $\leqslant 28$ weeks & $128.9(43.5)$ & $114.7-143.4$ & $74.1(46.6)$ & $67.1-81.1$ \\
\hline All $\leqslant 32$ weeks & $150.5(15.9)$ & $135.2-166.9$ & $105.5(12.6)$ & $94.6-117.6$ \\
\hline
\end{tabular}

* Actual and expected mortality (calculated from CRIB) for infants $\leqslant 32$ weeks and for infants $\leqslant 28$ weeks gestation is also shown

the Trent Health Region, which has a population of around 4.6 million with about 60000 births a year. All 16 perinatal services in Trent contribute to the study and units in adjacent regions also permit data collection on Trent infants. The survey was established in February 1990; the database holds information relating to all infants of 32 weeks gestation or less born to Trent resident mothers since that time.

In our previous investigation of survival of preterm infants, carried out between 1 February 1987 and 31 January 1988, we divided the 17 units active at the time into 5 "large" referral units and 12 "small" units. In the interim one small unit has closed, but in other respects the division remains valid. The five large units continue to take referrals on a regular basis and are the five most active units in the region. The other units accept very few outside referrals. In 1987 only one of the small units had a consultant with a special interest in neonatal medicine but now each unit has active consultant input. Similarly, the number of specialist neonatal nurses in the small units is now proportionately equivalent to those in the large units, a marked change to the situation in 1987.

Data for TNS are collected by five part time research nurses who regularly visit each of the neonatal units. They obtain information from the clinical records, discussions with staff and, where appropriate, personal observation.

CRIB was first described in 1993. The index is derived in the first 12 hours from six variables: birthweight; presence or absence of a congenital anomaly; gestation above or below 24 weeks; maximum base excess; maximum $\mathrm{FIO}_{2}$; minimum $\mathrm{FiO}_{2}$

The first three of these were part of the original TNS data set, the remainder were added for each baby born after 1 January 1994. Using CRIB to correct for disease severity, the following comparisons in survival were performed for babies born in Trent for the study period.

- All infants $\leqslant 32$ weeks gestation booked, born, and cared for in one of the five large units $v$ s all infants $\leqslant 32$ weeks gestation booked, born, and cared for in one of the 11 smaller units.
- All infants $\leqslant 28$ weeks gestation booked, born, and cared for in one of the five large units vs all infants $\leqslant 28$ weeks gestation booked, born, and cared for in one of the 11 smaller units.

- All infants $\leqslant 32$ weeks gestation not involved in any transfer $v$ s all infants $\leqslant 32$ weeks gestation involved in any sort of transfer (flying squad, in utero, or semi elective).

- All infants $\leqslant 28$ weeks gestation not involved in any transfer $v s$ all infants $\leqslant 28$ weeks gestation involved in any sort of transfer (flying squad, in utero, or semi elective).

- All infants $\leqslant 32$ weeks gestation involved in a flying squad transfer vs all infants $\leqslant 32$ weeks gestation involved in an in utero transfer.

- All infants $\leqslant 28$ weeks gestation involved in a flying squad transfer $v$ all infants $\leqslant 28$ weeks gestation involved in an in utero transfer.

In our previous investigation we assessed disease severity in each group using a range of clinical variables (birthweight, gestation, respiratory distress at birth, proportion of babies presenting by the breech, Apgar scores at 1 and 5 minutes, and multiple pregnancy rates). In that study these measures were broadly similar in the two groups, but significant differences existed for respiratory distress at birth, birthweight, and 5 minute Apgar score, indicating that babies in the large units were "sicker." For comparison, we repeated this exercise for infants born in 1994, 1995, and 1996.

Various statistical methods (including Student's $t$ test, Wilcoxon two tailed sample test and $\chi^{2}$, as appropriate) were used to examine differences in the clinical characteristics between the group of infants whose care was entirely in one of the large units and those whose care was entirely in one of the small units. CRIB was used to assess initial neonatal risk in each individual infant and from this information we derived an expected mortality rate for each of the populations indicated above.?

\section{Results}

Table 1 compares crude survival between small and large units for babies $\leqslant 32$ weeks gestation not involved in transfer of any kind, the method adopted in the 1987 study. In table 2 infants are shown categorised by birthweight, gestation, and whether they received ventilation. Among the whole group of infants $\leqslant 32$ weeks gestation mortality in the small units was significantly less $(16.9 \%$ vs $11.5 \%$; $\mathrm{p}$ <.001). Data from these two tables suggest that this effect occurs in infants $\geqslant 27$ weeks gestation; however, the tables also show that the group cared for in small units contained a far higher proportion of more mature infants. Straightforward statistical comparison of the two groups showed the population from large units to have been significantly smaller, more immature, given a lower 5 minute Apgar, more likely to be multiple births, more likely delivered by the breech and more likely to develop respiratory distress.

A similar crude comparison of mortality for infants: $\leqslant 28$ weeks gestation cared for in the two types of unit reveals a higher survival rate among infants whose care was entirely within the large units, but this difference was not significant. 
Table 2 Distribution of infants $\leqslant 32$ weeks gestation between small and large units subdivided by birthweight and gestation - non-transfers only - categorised by need for ventilation

\begin{tabular}{|c|c|c|c|c|c|c|c|c|}
\hline & \multicolumn{4}{|c|}{ Large } & \multicolumn{4}{|c|}{ Small } \\
\hline & \multicolumn{2}{|c|}{ Ventilated } & \multicolumn{2}{|c|}{ Not ventilated } & \multicolumn{2}{|c|}{ Ventilated } & \multicolumn{2}{|c|}{ Not ventilated } \\
\hline & & Died (\%) & & Died (\%) & & Died (\%) & & Died (\%) \\
\hline \multicolumn{9}{|c|}{ Gestation (weeks) } \\
\hline$\leqslant 22$ & 2 & $2(100)$ & 4 & $3(75.0)$ & 0 & & 3 & $3(100)$ \\
\hline $23-24$ & 43 & $33(76.7)$ & 2 & $2(100)$ & 33 & $32(97.0)$ & 0 & \\
\hline $25-26$ & 99 & $47(47.5)$ & 3 & $2(100)$ & 33 & $19(57.6)$ & 1 & $0(0)$ \\
\hline $27-28$ & 123 & $37(30.1)$ & 20 & $0(0)$ & 83 & $22(26.5)$ & 6 & $0(0)$ \\
\hline $29-30$ & 140 & $18(12.9)$ & 65 & $0(0)$ & 118 & $10(8.5)$ & 82 & $2(2.4)$ \\
\hline $31-32$ & 130 & $15(11.5)$ & 317 & $0(0)$ & 137 & $8(5.8)$ & 340 & $0(0)$ \\
\hline \multicolumn{9}{|l|}{ Birthweight (g) } \\
\hline$<500$ & 4 & $2(50.2)$ & 2 & $2(100)$ & 2 & $2(100)$ & 3 & $3(100)$ \\
\hline $500-749$ & 77 & $52(67.5)$ & 6 & $5(83.3)$ & 43 & $35(81.4)$ & 0 & \\
\hline $750-999$ & 116 & $51(44.0)$ & 10 & $1(10.0)$ & 48 & $21(42.9)$ & 14 & $0(0)$ \\
\hline $1000-1249$ & 110 & $20(18.2)$ & 45 & $0(0)$ & 98 & $16(16.3)$ & 53 & $1(1.9)$ \\
\hline $1250-1499$ & 106 & $10(9.4)$ & 83 & $0(0)$ & 87 & $8(9.2)$ & 98 & $1(1.0)$ \\
\hline $1500+$ & 124 & $17(13.7)$ & 265 & $0(0)$ & 125 & $9(7.2)$ & 264 & $0(0)$ \\
\hline Total & 537 & $152(28.3)$ & 411 & & 404 & $91(22.5)$ & 432 & $5(1.2)$ \\
\hline
\end{tabular}

Also shown in table 1 are CRIB data relating to the same two groups of babies (nontransfers $\leqslant 32$ weeks and non-transfers $\leqslant 28$ weeks) split between small and large units. In each case actual mortality falls within the $95 \%$ confidence interval of the CRIB estimate-that is, in both settings and in both gestation groups mortality falls within the acceptable range as defined by CRIB.

Tables 3 and 4 include information about actual and expected mortality for those babies involved in transfer. Again, there is no suggestion that any of the subgroups identified have a worse than predicted outcome, irrespective of whether the transfer occurred before or after delivery.

None of the above adequately quantifies the extent to which selection affects the work carried out in the different settings. For example, small units may choose to transfer all of their most immature infants if they appear viable and retain only those where death is considered inevitable; large units, by providing high risk pregnancy services, may attract particularly complex cases; both types of unit may adopt a policy of admitting all live born infants even if they are considered non-viable and may or may not offer those babies intensive

Table 3 Actual and expected (calculated from CRIB) mortality for infants $\leqslant 32$ weeks not involved in any trnasfer; involved in any form of transfer (neonatal flying squad, in utero or non-urgent; transferred as an emergency after delivery (neonatal flying squad); transferred in utero for neonatal care in another hospital

\begin{tabular}{lllll}
\hline Type of infant & $\begin{array}{l}\text { No of infants } \\
\leqslant 32 \text { weeks } \\
\text { gestation }\end{array}$ & $\begin{array}{l}\text { Mortality of } \\
\text { infants } \leqslant 32 \\
\text { weeks (\%) }\end{array}$ & $\begin{array}{l}\text { Predicted (CRIB) } \\
\text { mortality of infants } \\
\leqslant 32 \text { weeks (\%) }\end{array}$ & $\begin{array}{l}\text { 95\% CI for } \\
\text { estimate of } \\
\text { expected mortality }\end{array}$ \\
\hline Non-tranfers & 1784 & $256(14.3)$ & $252(14.1)$ & $230.1-275.5$ \\
Transfer (all types) & 754 & $137(18.2)$ & $141(18.7)$ & $129-153.7$ \\
Flying squad transfers & 235 & $57(24.3)$ & $60.2(25.9)$ & $51.5-69.6$ \\
In utero transfers & 353 & $68(19.2)$ & $64.8(18.2)$ & $54.8-76.2$ \\
\hline
\end{tabular}

Table 4 Actual and expected (calculated from CRIB) mortality for infants $\leqslant 28$ weeks not involved in any trnasfer; involved in any form of transfer (neonatal flying squad, in utero or non-urgent; transferred as an emergency after delivery (neonatal flying squad); transferred in utero for neonatal care in another hospital

\begin{tabular}{lllll}
\hline Type of infant & $\begin{array}{l}\text { No of infants } \\
\leqslant 28 \text { weeks } \\
\text { gestation }\end{array}$ & $\begin{array}{l}\text { Mortality of } \\
\text { infants } \leqslant 28 \\
\text { weeks (\%) }\end{array}$ & $\begin{array}{l}\text { Predicted (CRIB) } \\
\text { mortality of infants } \\
\leqslant 28 \text { weeks (\%) }\end{array}$ & $\begin{array}{l}\text { 95\% CI for } \\
\text { estimate of } \\
\text { expected mortality }\end{array}$ \\
\hline Non-tranfers & 455 & $203(44.6)$ & $190.9(42.0)$ & $174.3-207.8$ \\
Transfer (all types) & 318 & $113(35.5)$ & $125.1(39.3)$ & $113.2-137.2$ \\
Flying squad transfers & 113 & $47(41.6)$ & $49.1(43.5)$ & $41.4-56.9$ \\
In utero transfers & 139 & $59(42.4)$ & $56.9(40.9)$ & $47.6-66.5$ \\
\hline
\end{tabular}

care. The CRIB data, by quantifying disease severity, highlight phenomena which are almost certainly the end product of such selection. The whole population of infants $\leqslant 32$ weeks gestation cared for by the larger units had significantly higher disease severity scores than those in the smaller units (expected mortality $15.9 \% \quad(14.3-17.6)$ vs $12.6 \%$ (11.314.1). The group of babies $\leqslant 32$ weeks gestation transferred had a significantly greater predicted mortality than those who received all their neonatal care in one unit (expected mortality $18.7 \%(17.1-20.3)$ vs $14.1 \%$ (13.215.4) - as might be expected the process of transfer appeared to select for a population of babies who were more severely ill). This was particularly apparent among postnatal flying squad transfers. But babies $\leqslant 28$ weeks gestation had no significant difference in disease severity between those cared for in large and small units. In this group those transferred tended to be less severely ill compared with those cared for in a single unit, and to have a survival rate significantly better than predicted.

\section{Discussion}

The figures for survival corrected for initial disease severity are of prime importance. They indicate quite clearly that outcome was equally good for all babies $\leqslant 32$ weeks gestation, irrespective of the type of unit that provided their neonatal care. Taking the study population as a whole, there is evidence that the service is working in an integrated manner. The larger units, appropriately, attract a group of infants who are sicker than those whose care is entirely in the smaller units. The babies transferred for neonatal care tend to be sicker than those that normally receive treatment in the small units.

Focusing on babies: $\leqslant 28$ weeks gestation reveals a slightly different pattern. Here CRIB scores indicate that those infants not involved in transfer are similar, in terms of disease severity, in both types of unit and outcomes are equally good. Those babies that are transferred do not have a higher predicted mortality. This suggests that, among these infants, selection for transfer relies on different criteria; possibly, some infants are felt to be too sick or too immature to move from the smaller units. 
In our 1987 study we identified worse outcome in terms of crude mortality for non-transferred infants $\leqslant 28$ weeks gestation when care had been delivered in one of the small units. In the current study a similar comparison of all non-transferred infants $\leqslant 32$ weeks gestation has shown a significantly better outcome for infants whose care was in the small units. In this current study CRIB puts in context the observed differences in mortality, something that was not possible as part of the 1987 investigation. However, we feel that the 1987 findings remain valid in relation to the service that existed at that time. Although we have not been able to apply retrospectively the CRIB score to the 1987 cohort, we know that descriptive variables associated with increased disease severity (presence of respiratory distress, lower birthweight, and lower 5 minute Apgar score) were significantly more common in the infants cared for in the large units at that time. For the 1987 findings to be invalid disease severity among babies in the smaller units would have to have been significantly higher than those in the larger centres, and this seems unlikely. These arguments show that a qualitative approach to assessing disease severity is limited in its usefulness and CRIB provides a much more objective framework to deal with these issues in future.

Given the improved levels of specialist medical and nursing input since 1987, it is plausible that differences in survival should have disappeared between both types of unit. But it is crucial to understand that these excellent results have not occurred by chance and that adequate resourcing of staff, equipment, and infrastructure are essential. The small units in Trent that undertake intensive care still rely on the large referral centres to help with peaks in demand, to provide subspecialty support, and for most specialist training. It is important, therefore, that the role of the large units within the current system is preserved to maintain the present co-operative working arrangements. We welcome the increased availability of good local care, but the current funding arrangements do not satisfactorily address issues of complexity of care, training, and service development. Dealing with these remains a challenge for the NHS.

Recent data from other parts of the developed world identify a different situation. Based on data from the United States in the early 1990s, Phibbs et al noted that neonatal units with a high throughput of intensive care appeared to have lower mortality rates. However, their report contains important methodological differences relative to the data we present here, especially with regard to the measurement of disease severity, which in the US study relied heavily on diagnosis. There are also major differences in the US and UK health care systems, which limit the extent to which the study can be usefully considered in relation to neonatal care in the UK.

Phibbs et al identified a higher mortality for infants transferred for intensive care, consistent with previously published work ${ }^{9}$; this finding is often a feature of neonatal units' annual reports. This poorer outcome has been variously ascribed to inadequate care before transfer or the process of transfer itself. Our data seem to indicate that, for babies $\leqslant 32$ weeks, the transferred infants simply represent a selected sicker group whose outcome is as predicted. To understand this effect more clearly, the CRIB score should be calculated at various points during the first 12 hours of life and the values obtained for infants involved in transfer compared with babies whose care is entirely in one unit. This approach differs from normal, in that CRIB is usually calculated just once on information related to the whole of the first 12 hours of life.

The use of CRIB remains controversial; some clinicians are concerned it does not adequately reflect complexity of care and clinical practice. Indeed, the group that originally developed CRIB have recently identified problems when CRIB is used to compare individual hospitals over short time spans. ${ }^{10}$ Their study, however, endorsed the type of approach taken here - that is, assessing groups of hospitals involving large numbers of infants over significant periods of time. We accept that the use of CRIB does not adequately reflect all aspects of policy. In particular, policies of admitting non-viable infants for terminal care and decisions about which infants to transfer-for example, whether to move the sickest or only those thought to have a reasonable chance of survival - distort the figures. The use of CRIB, as described here, permits, a broad assessment of policy in terms of service delivery and provides opportunities both to understand survival figures better and also to know how they might be improved.

We have not considered morbidity, which is clearly of major importance. Comparisons based on later outcomes will not be possible until a simple standardised method of review is more widely available across the UK. ${ }^{11}$

We thank the staff (medical, nursing, and clerical) of the 16 perinatal units in Trent for their continuing help and cooperation. We are most grateful to those units adjacent to Trent that allow us access to data on cross boundary flows of patients.

1 Botting B, ed. The Health of Our Children. Decennial supplement. Office of Population Censuses and Surveys Supplement. Office D S No 11. London: The Stationery Office, 1995.

2 Field D, Hodges S, Mason E, Burton P. Survival and place of treatment after premature delivery. Arch Dis Child of treatment a 66 :408-11.

3 Paneth N, Kiely JL, Wallenstein S, Marcus M, Parker J, Susser M. Newborn intensive care and neonatal mortality in low birth-weight infants. Population study. $N$ Engl $\mathcal{F}$ Med 1982;307:149-55.

4 Verloove-Vanhorick SP, Verwey RA, Ebeling MCA, Brand $\mathrm{R}$, Ruys JH. Mortality in very preterm and low birthweight infants according to place of delivery and level of care: results of a national collaborative survey of preterm and very low birth weight infants in The Netherlands. Pediatrics 1988;81:404-11.

5 Pope C, Wild D. Putting the clock-back thirty years: neonatal services since the 1991 NHS reforms. Arch Dis Child 1992;67:879-81.

6 Clinical Standards Advisory Group. Access and availability of neonatal intensive care. London: CSAG, 1995.

7 The International Neonatal Network. The CRIB (clinical risk index for babies) score: a tool for assessing initial neonatal risk and comparing performance of neonatal units. Lancet 1993;342:193-8.

8 Phibbs CS, Bronstein JM, Buxton E, Phibbs RH. The effects of patient volume and level of care at the hospital of birth on neonatal mortality. FAMA 1996;276:1054-9.

9 Harding JE, Morton SM. Adverse effects of transport between level iii units. $\mathcal{F}$ Paediatr Child Health 1993;29:146-9.

10 Parry GJ, Gould CR, Mc Cabe CJ, et al. Annual league tables of mortality in neonatal intensive care units: longitudinal study. BMF 1998;316:1931-5.

11 NPEU. Disability and perinatal care: measurement at 2 years. A report of 2 working groups convened by the National Perinatal Epidemiology Unit and Oxford Regional Health natal Epidemiology Unit and
Authority. Oxford: NPEU, 1994. 